\title{
A Pilot Study of the Association of Low Plasma Adiponectin and Barrett's Esophagus
}

\author{
Joel H. Rubenstein, M.D., M.Sc., ${ }^{1,2}$ Anne Dahlkemper, B.A., ${ }^{2}$ John Y. Kao, M.D., ${ }^{2}$ Min Zhang, M.D., ${ }^{2}$
}

Hal Morgenstern, Ph.D., ${ }^{3}$ Laurence McMahon, M.D., M.P.H., ${ }^{1,2}$ and John M. Inadomi, M.D. ${ }^{4}$

${ }^{1}$ Ann Arbor Veterans Affairs Medical Center, Ann Arbor, Michigan; ${ }^{2}$ University of Michigan Medical School, Ann Arbor, Michigan; ${ }^{3}$ University of Michigan School of Public Health, Ann Arbor, Michigan; and ${ }^{4}$ GI Health Outcomes, Policy and Economics (HOPE) Research Program, University of California, San Francisco, and the San Francisco General Hospital, San Francisco, California

BACKGROUND Gastroesophageal reflux disease (GERD) and obesity are associated with esophageal AND AIMS: $\quad$ adenocarcinoma (EAC). We hypothesized that the obesity-EAC relation is mediated by factors secreted from adipocytes. Adiponectin is a peptide secreted by adipocytes, and its plasma levels are inversely associated with obesity. We aimed to estimate the effect of circulating adiponectin on the risk of Barrett's esophagus (BE), an accepted precursor of EAC, controlling for GERD symptoms and other potential confounders.

METHODS: $\quad$ We conducted a case-control study in cases of BE compared with controls without BE; most controls had GERD. Odds ratios (OR), corresponding to associations with BE, were estimated from conditional and unconditional logistic regression analyses of 50 matched pairs.

RESULTS: $\quad$ BE was inversely associated with plasma adiponectin level (OR for each $10-\mu \mathrm{g} / \mathrm{mL}$ decrement 4.7 , $95 \%$ confidence interval $[\mathrm{CI}]$ 1.4-15.0) and positively associated with GERD duration $\geq 10 \mathrm{yr}$, male gender, tobacco smoking, body mass index (BMI), waist circumference, and waist-to-hip ratio. Further adjustment for GERD duration, tobacco use, and BMI increased the adiponectin-BE association (OR 6.4, 95\% $\mathrm{Cl}$ 1.1-37.0), but the estimated OR was reduced when adjusting for measures of abdominal obesity (e.g., OR 2.5, 95\% $\mathrm{Cl}$ 0.49-13.00) and further adjusting for gender (OR 1.8, 95\% Cl 0.66-4.70).

CONCLUSIONS: Despite methodologic limitations, including the small sample size, our findings suggest that adiponectin may be involved in the etiology of BE. Rather than simply a mechanical effect of obesity promoting GERD, the effects of abdominal obesity on the risk of BE might be mediated by adiponectin and other circulating factors.

(Am J Gastroenterol 2008;103:1358-1364)

\section{INTRODUCTION}

The incidence of esophageal adenocarcinoma (EAC) in the United States is rising faster than that of any other cancer (1). Barrett's esophagus (BE) is associated with most, if not all, EACs (2-4). Risk factors for EAC include gastroesophageal reflux disease (GERD) and obesity $(2,3,5)$. Obesity has also been associated with GERD (5). Therefore, the effect of obesity on EAC has been proposed to be mediated by a mechanical effect promoting GERD, and thereby promoting BE $(6,7)$. As obesity is associated with EAC, even after adjusting for $\operatorname{GERD}(5,8)$, we hypothesized that the effect of obesity on EAC and BE may not be solely due to the promotion of GERD. Prior studies have shown an association between abdominal obesity and BE, but no association, or a weaker association, between total body obesity and BE (9-11). Abdominal adipose tissue is biologically active; circulating factors secreted from adipose tissue may mediate part of the effect of obesity on the development of BE, EAC, or both. Candidate circulating factors include interleukin-6, tumor necrosis factor- $\alpha$, leptin, ghrelin, adiponectin, insulin-like growth factor-1 or its binding proteins, and others (12-17). Adiponectin is a peptide secreted primarily from visceral adipocytes, for which serum levels are inversely associated with obesity (18). Levels are lower in men than in women, controlling for obesity (19). Adiponectin inhibits inflammation and promotes apoptosis, and deficiency of adiponectin has been associated with a number of epithelial cancers (18). We chose a priori to evaluate the role of adiponectin because of these features and due to its stable intrasubject levels across time and in relation to meals (20-24). We hypothesized that adiponectin deficiency is a risk factor for BE and performed a case-control study to examine the association between circulating levels of adiponectin and $\mathrm{BE}$ among patients undergoing elective upper endoscopy. 


\section{METHODS}

\section{Subjects}

The study was performed at the University of Michigan Medical Center and the Ann Arbor Veterans Affairs Medical Center. Both centers provide a mix of primary, secondary, and tertiary care. Both cases and controls were recruited when they presented with clinical indications for elective upper endoscopy. Cases were patients with $\mathrm{BE}$ of at least $1 \mathrm{~cm}$ in length (for the most part, these were prevalent cases), confirmed by histological identification of specialized intestinal metaplasia within the tubular esophagus. Controls were patients without BE, who were individually matched to cases on age (15-yr interval) and veteran/civilian status. If subjects carried a diagnosis of $\mathrm{BE}$ from a previous endoscopy, but BE was not confirmed by the endoscopy and biopsies at the time of the study ( $\mathrm{N}=8$, all short-segment on prior endoscopy reports), they were not matched and were excluded from the analysis. Patients were excluded from enrollment if they had prevalent cancer, ascites, esophageal varices, coagulopathy, or a history of esophagectomy, were pregnant, were a hospital inpatient, were younger than 18 or greater than $79 \mathrm{yr}$ of age, or if the indication for endoscopy was weight loss of $\geq 10 \%$ or for placement of a feeding tube. The sample size for the analyses presented is 50 matched case-control pairs. The study was approved by the institutional review boards of both centers, and all subjects provided written, informed consent prior to enrollment.

\section{Questionnaire and Anthropometry}

Subjects were asked to complete self-administered questionnaires just prior to the endoscopy. A set of questions regarding the presence, duration, quality, frequency of, and medications for GERD symptoms, including heartburn and reflux, was based on variables previously found to be associated with EAC (25). The questionnaires also queried history of tobacco use. An important potential confounder of adiponectin deficiency would be abdominal obesity, which is associated with both adiponectin deficiency and BE. Weight, height, abdominal circumference, and hip circumference were measured by a trained assistant prior to the endoscopy, while the subject wore only a hospital gown and undergarments.

\section{Blood Samples}

Fasting blood samples were drawn prior to the upper endoscopy. Plasma was separated and stored at $-80^{\circ} \mathrm{C}$ until analyzed in duplicate for adiponectin using a commercially available colorimetric sandwich enzyme-linked immunosorbent assay (B-Bridge, Sunnyvale, CA). We examined the specificity of the relation between $\mathrm{BE}$ and adiponectin by examining a similar relation between $\mathrm{BE}$ and $\mathrm{C}$-reactive protein (CRP), serum levels of which are also associated with obesity and have been associated with colorectal cancer $(26,27)$. CRP was measured quantitatively in the clinical laboratory of the Ann Arbor VA using the highly sensitive near-infrared particle immunoassay methodology.

\section{Endoscopy and Histology}

Upper endoscopy was performed by clinical gastroenterologists at both study sites. The trained assistant was present for all endoscopies and directed the endoscopists to abide by standardized guidelines for diagnosing $\mathrm{BE}$, hiatal hernia, and erosive esophagitis. These guidelines, with example photographs, were posted in each endoscopy room at both study sites. Digital photographs were obtained of the gastroesophageal junction and the squamocolumnar junction in each subject. The photographs were subsequently reviewed by the principal investigator (JHR) to confirm the endoscopic appearance of BE. BE was suspected if salmon-colored mucosa resided proximal to the gastric folds within the tubular esophagus. The length of BE was documented, and four-quadrant mucosal biopsies were obtained every $2 \mathrm{~cm}$ for histologic confirmation. The presence and size of any hiatal hernia was documented. One subject with Los Angeles Classification C erosive esophagitis underwent repeat endoscopy after a healing course with a proton pump inhibitor, revealing normal squamous lining. No other subjects without evidence of $\mathrm{BE}$ on index endoscopy had erosive esophagitis that was more severe than class B. Pathology specimens were prepared according to the routine clinical protocol and interpreted by clinical pathologists at each study site. The presence of specialized intestinal columnar mucosa was required for the diagnosis of BE.

\section{Statistical Analysis}

Data were entered into Microsoft Access (Microsoft Corporation, Redmond, WA), and then imported into SAS 9.1 statistical software for analysis (SAS Institute, Cary, NC). Data were assessed for range and logic inconsistencies. Crosstabs for categorical predictors and correlation coefficients for continuous predictors were used to assess associations between pairs of possible BE predictors among controls. Conditional logistic regression analysis was used to estimate the effect (odds ratio [OR] and 95\% confidence interval [CI]) of adiponectin and other factors on BE, controlling for the matching variables. Results are presented for several models, involving adjustment for combinations of GERD duration, smoking history, gender, body mass index (BMI), waist circumference, and waist-to-hip ratio (WHR). Because of the small sample size (50 matched pairs) and the strong association between gender (a known risk factor for $\mathrm{BE}$ ) and veteran/civilian status (a matching variable), we were not able to adjust for gender plus other covariates in the matched analysis. Thus, separate unconditional logistic regression analyses were conducted, adjusting for the matching variable age but not veteran/civilian status. Age was treated as a continuous variable as similar results were found when using age as a set of indicator variables. In addition, unconditional logistic regression was performed in a set restricted to subjects with GERD symptoms at least once per week while not taking proton pump inhibitors or histamine type 2 receptor antagonists. 


\section{RESULTS}

As expected, cases and controls were similar in the matching variables: the mean age was $60 \mathrm{yr}$ in both groups, and $36 \%$ of each group was of veterans. Most subjects were white, $92 \%$ in cases and $96 \%$ in controls; $80 \%$ of cases and $54 \%$ of controls were men. Among controls, the most common indications for the endoscopy were GERD refractory to medications (33\%), dysphagia (22\%), screening for BE (18\%), and irondeficiency anemia (10\%). Among cases of BE, $84 \%$ were undergoing endoscopy for surveillance of known BE (median time since diagnosis was $5 \mathrm{yr}$, interquartile range 3-8 yr), and the median length of the columnar segment was $3.0 \mathrm{~cm}$ (range 1.0-18.0 cm). Four cases of BE were found to have low-grade dysplasia, two were found to have high-grade dysplasia, and two were found to have invasive adenocarcinoma.

Among controls, the mean plasma level of adiponectin was $11.4 \mu \mathrm{g} / \mathrm{mL}$, ranging from 1.4 to $29.3 \mu \mathrm{g} / \mathrm{mL}$. Waist circumference was highly correlated with WHR or BMI among controls without BE (Pearson's correlation coefficient $[\mathrm{r}]=$ $0.71, P<0.0001$ for waist circumference and WHR; $\mathrm{r}=$ $0.80, P<0.0001$ for waist circumference and BMI). However, BMI and WHR were less correlated with each other (r $=0.22, P=0.12$ ). Adiponectin levels were weakly to moderately correlated with WHR $(\mathrm{r}=-0.37, P=0.008)$, waist circumference $(\mathrm{r}=-0.40, P=0.005)$, BMI $(\mathrm{r}=-0.19, P$ $=0.18)$, and age $(\mathrm{r}=0.38, P=0.007)$, and nearly uncorrelated with GERD duration $(\mathrm{r}=-0.01, P=0.92)$. Male controls trended toward lower levels of adiponectin than female controls (mean \pm standard deviation $10.3 \pm 6.6 \mu \mathrm{g} / \mathrm{mL}$ $v s 12.6 \pm 5.6 \mu \mathrm{g} / \mathrm{mL}, P=0.19)$. Veteran and civilian controls had similar adiponectin levels $(11.2 \pm 6.6 \mu \mathrm{g} / \mathrm{mL} v s 11.5 \pm$ $6.1 \mu \mathrm{g} / \mathrm{mL}, P=0.89)$. Among cases of BE, the mean plasma level of adiponectin was $8.4 \mu \mathrm{g} / \mathrm{mL}$, ranging from 1.6 to 18.6 $\mu \mathrm{g} / \mathrm{mL}$. Adiponectin was weakly correlated with the number of years since the initial diagnosis of $\mathrm{BE}(\mathrm{r}=0.24, P=0.14)$.

Conditional logistic regression analysis showed that longer GERD duration, male gender, BMI, waist circumference, and WHR were all associated with BE (Table 1, models B-F). As hypothesized, lower levels of circulating adiponectin were also associated with BE: for each $10-\mu \mathrm{g} / \mathrm{mL}$ decrement in adiponectin, there was an increased odds of BE (OR 4.7, 95\% CI 1.4-15.0). Level of CRP was not associated with BE (OR $0.99,95 \%$ CI 0.64-1.50). The estimated effect of adiponectin was not reduced when adjusting for GERD duration, smoking status, and BMI (Table 1, model J). When adjusting for abdominal obesity, however, the estimated effect of adiponection was reduced; for example, adjusting for WHR plus the other covariates, the OR for adiponectin deficiency was 2.5 (95\% CI 0.49-13.00) (Table 1, models K and L).

In order to adjust for gender, we broke the matched pairs and used unconditional logistic regression to estimate effects, adjusting for age but not veteran/civilian status. After adjusting for gender, the estimated effect of adiponectin on $\mathrm{BE}$ was reduced, but not eliminated, in these analyses (Table 2). For example, adjusting for age, GERD duration, gender, and
Table 1. Odds Ratios for the Association Between Predictors and Barrett's Esophagus: Results of Conditional Logistic Regression Analyses

\begin{tabular}{|c|c|c|}
\hline Model & Covariate & OR $(95 \% \mathrm{CI})$ \\
\hline A & $\begin{array}{l}\text { Adiponectin }(10-\mu \mathrm{g} / \mathrm{mL} \\
\text { decrement })^{*}\end{array}$ & $4.7(1.4-15.0)$ \\
\hline $\mathrm{B}$ & GERD duration $\geq 10 \mathrm{yr} v s<10 \mathrm{yr}$ & $2.9(1.2-6.8)$ \\
\hline $\mathrm{C}$ & Ever smoker $v s$ never smoker & $6.3(1.9-21.0)$ \\
\hline $\mathrm{D}$ & BMI (5-kg/m² increment)* & $1.5(1.0-2.4)$ \\
\hline $\mathrm{E}$ & $\begin{array}{l}\text { Waist circumference (10-cm } \\
\text { increment)* }\end{array}$ & $1.6(1.1-2.2)$ \\
\hline $\mathrm{F}$ & Waist/hip ratio (0.1 increment)* & $2.6(1.5-4.7)$ \\
\hline G & $\mathrm{CRP}(1-\mathrm{mg} / \mathrm{L} \text { increment })^{*}$ & $0.99(0.64-1.50)$ \\
\hline \multirow[t]{2}{*}{$\mathrm{H}$} & $\begin{array}{l}\text { Adiponectin }(10-\mu \mathrm{g} / \mathrm{mL} \\
\text { decrement })^{*}\end{array}$ & $4.4(1.3-14.0)$ \\
\hline & GERD duration $\geq 10 \mathrm{yr} v s<10 \mathrm{yr}$ & $2.7(1.1-6.8)$ \\
\hline \multirow[t]{3}{*}{ I } & $\begin{array}{l}\text { Adiponectin }(10-\mu \mathrm{g} / \mathrm{mL} \\
\text { decrement })^{*}\end{array}$ & $5.8(1.2-27)$ \\
\hline & GERD duration $\geq 10 \mathrm{yr} v s<10 \mathrm{yr}$ & $3.0(0.89-10.00)$ \\
\hline & Ever smoker $v s$ never smoker & $7.1(1.7-29.0)$ \\
\hline \multirow[t]{4}{*}{$\mathrm{J}$} & $\begin{array}{l}\text { Adiponectin }(10-\mu \mathrm{g} / \mathrm{mL} \\
\text { decrement)* }\end{array}$ & $6.4(1.1-37.0)$ \\
\hline & GERD duration $\geq 10 \mathrm{yr} v s<10 \mathrm{yr}$ & $3.0(0.84-10.00)$ \\
\hline & Ever smoker $v s$ never smoker & $7.5(1.7-33.0)$ \\
\hline & BMI (5-kg/m² increment) $)^{*}$ & $0.87(0.42-1.80)$ \\
\hline \multirow[t]{4}{*}{$\mathrm{K}$} & Adiponectin $(10-\mu \mathrm{g} / \mathrm{mL} \text { decrement })^{*}$ & $4.9(0.79-30.00)$ \\
\hline & GERD duration $\geq 10 \mathrm{yr} v s<10 \mathrm{yr}$ & $2.8(0.75-11.00)$ \\
\hline & Ever smoker $v s$ never smoker & $6.7(1.6-29.0)$ \\
\hline & $\begin{array}{l}\text { Waist circumference }(10-\mathrm{cm} \\
\text { increment)* }\end{array}$ & $1.1(0.68-1.70)$ \\
\hline \multirow[t]{4}{*}{$\mathrm{L}$} & $\begin{array}{l}\text { Adiponectin }(10-\mu \mathrm{g} / \mathrm{mL} \\
\text { decrement })^{*}\end{array}$ & $2.5(0.49-13.00)$ \\
\hline & GERD duration $\geq 10 \mathrm{yr} v s<10 \mathrm{yr}$ & $2.3(0.57-9.00)$ \\
\hline & Ever smoker $v s$ never smoker & $6.0(1.3-27.0)$ \\
\hline & Waist/hip ratio (0.1 increment) ${ }^{*}$ & $1.7(0.84-3.50)$ \\
\hline
\end{tabular}

Each model only included the covariates for which results are displayed (1-4 covariates in each model); for instance, model L included adiponectin, GERD duration, smoking status, and waist/hip ratio.

*The odds ratio for a continuous predictor is estimated for a specified difference in that exposure (indicated in parentheses after the predictor).

OR $(95 \% \mathrm{CI})=$ odds ratio $(95 \%$ confidence interval $)$; $\mathrm{BMI}=$ body mass index; CRP $=\mathrm{C}$-reactive protein

WHR, the estimated OR for adiponectin deficiency was 1.8 (95\% CI 0.66-4.70). The estimated effect of male gender was reduced after adjusting for adiponectin, and reduced more so after adjusting for WHR. Restricting the analyses to subjects with GERD symptoms at least once per week while off proton pump inhibitors or histamine type 2 receptor antagonists ( 45 cases of BE and 34 controls) resulted in similar estimates of the adiponectin effect (Table 3). For example, adjusting for age, gender, and WHR, the estimated OR for adiponectin deficiency was 1.7 (95\% CI 0.60-4.90). Current or past tobacco smoking remained strongly associated with $\mathrm{BE}$ in all analyses.

\section{DISCUSSION}

In our case-control study of $50 \mathrm{BE}$ cases and matched controls undergoing elective endoscopy for other clinical indications, we found an inverse association between the circulating 
Table 2. Odds Ratios for the Association Between Predictors and Barrett's Esophagus: Results of Unconditional Logistic Regression Analyses Adjusted for Age

\begin{tabular}{lll}
\hline Model & \multicolumn{1}{c}{ Covariate } & \multicolumn{1}{c}{ OR $(95 \% \mathrm{CI})$} \\
\hline $\mathrm{A}$ & Male $v$ f female & $4.5(1.8-12.0)$ \\
$\mathrm{B}$ & Adiponectin $(10-\mu \mathrm{g} / \mathrm{mL} \text { decrement })^{*}$ & $2.3(0.97-5.60)$ \\
& Male $v s$ female & $3.2(1.2-8.8)$ \\
$\mathrm{C}$ & Male $v$ female & $1.4(0.40-4.90)$ \\
& Waist/hip ratio $(0.1 \mathrm{increment})^{*}$ & $2.3(1.2-4.2)$ \\
$\mathrm{D}$ & Adiponectin $(10-\mu \mathrm{g} / \mathrm{mL} \text { decrement })^{*}$ & $2.4(0.95-6.10)$ \\
& GERD duration $\geq 10 \mathrm{yr} v s<10 \mathrm{yr}$ & $3.9(1.5-10.0)$ \\
& Male $v s$ female & $3.3(1.2-9.2)$ \\
$\mathrm{E}$ & Adiponectin $(10-\mu \mathrm{g} / \mathrm{mL} \text { decrement })^{*}$ & $1.9(0.76-4.90)$ \\
& GERD duration $\geq 10 \mathrm{yr} v s<10 \mathrm{yr}$ & $4.0(1.5-11.0)$ \\
& Male $v s$ female & $3.8(1.2-11.0)$ \\
& BMI $\left(5-\mathrm{kg} / \mathrm{m}^{2} \text { increment }\right)^{*}$ & $1.6(0.99-2.50)$ \\
$\mathrm{F}$ & Adiponectin $(10-\mu \mathrm{g} / \mathrm{mL} \text { decrement })^{*}$ & $1.8(0.69-4.70)$ \\
& GERD duration $\geq 10 \mathrm{yr} v s<10 \mathrm{yr}$ & $3.9(1.4-11.0)$ \\
& Male $v s$ female & $2.7(0.90-7.90)$ \\
& Waist circumference $(10-\mathrm{cm} \text { increment })^{*}$ & $1.4(0.99-1.90)$ \\
$\mathrm{G}$ & Adiponectin $(10-\mu \mathrm{g} / \mathrm{mL} \text { decrement })^{*}$ & $1.8(0.66-4.70)$ \\
& GERD duration $\geq 10 \mathrm{yr} v s<10 \mathrm{yr}$ & $3.5(1.3-9.5)$ \\
& Male $v s$ female & $1.4(0.39-5.40)$ \\
& Waist/hip ratio $(0.1 \mathrm{increment})^{*}$ & $1.9(0.99-3.60)$ \\
\hline
\end{tabular}

Each model only included the covariates for which results are displayed (1-4 covariates in each model), plus age as a continuous variable.

*The odds ratio for a continuous predictor is estimated for a specified difference in that exposure (indicated in parentheses after the predictor).

OR $(95 \% \mathrm{CI})=$ odds ratio $(95 \%$ confidence interval $)$; $\mathrm{BMI}=$ body mass index; $\mathrm{CRP}$ $=\mathrm{C}$-reactive protein.

level of adiponectin and the presence of BE. The magnitude of this association was not reduced when adjusting for GERD, tobacco use, and BMI; however, adjustment for gender and abdominal obesity did reduce the association. Although these latter adjustments did not eliminate the association between adiponectin and BE, the small sample size resulted in imprecise OR estimates (wide CIs), making chance an alternative explanation for these findings.

Research on the pathogenesis of BE and EAC has largely focused on GERD as an etiologic agent. However, approximately $40 \%$ of EAC patients report never having had GERD symptoms $(2,28)$. Furthermore, animal models of severe erosive esophagitis are inefficient at producing the complications of $\mathrm{BE}$ or EAC, suggesting that other factors may be necessary (29). Genetic predisposition may be one such factor, but the human species cannot be evolving rapidly enough to account for the increasing incidence of EAC over the last few decades (1). An environmental or behavioral cause is much more likely. We found that among patients referred for endoscopy, most with GERD, those diagnosed with BE are more likely to have smoked than those patients without BE, raising the possibility that smoking is a risk factor for BE. Nonetheless, tobacco use is on the wane in the United States. In contrast, Jeon et al. have shown that the period effect on the gender- and age-specific prevalence of obesity matches the period effect on the gender- and age-specific incidence of EAC over the last decades, suggesting a possible causal link (30). While obesity may promote GERD by mechanical or physiologic mechanisms, the association of obesity with
Table 3. Odds Ratios for the Association Between Predictors and Barrett's Esophagus Among GERD Patients: Results of Unconditional Logistic Regression Analyses Adjusted for Age, Restricted to Subjects With GERD at Least Once per Week (45 Cases and 34 Controls)

\begin{tabular}{|c|c|c|}
\hline Model & Covariate & OR $(95 \% \mathrm{CI})$ \\
\hline $\bar{A}$ & Adiponectin $(10-\mu \mathrm{g} / \mathrm{mL} \text { decrement })^{*}$ & $3.1(1.2-7.9)$ \\
\hline $\mathrm{B}$ & GERD duration $\geq 10 \mathrm{yr} v s<10 \mathrm{yr}$ & $2.6(0.88-7.60)$ \\
\hline $\mathrm{C}$ & Ever smoker $v s$ never smoker & $6.4(2.2-19.00)$ \\
\hline $\mathrm{D}$ & BMI $\left(5-\mathrm{kg} / \mathrm{m}^{2} \text { increment }\right)^{*}$ & $1.5(0.96-2.40)$ \\
\hline $\mathrm{E}$ & Waist circumference (10-cm increment)* & $1.5(1.1-2.1)$ \\
\hline $\mathrm{F}$ & Waist/hip ratio (0.1 increment)* & $2.3(1.3-3.8)$ \\
\hline $\mathrm{G}$ & Male $v s$ female & $4.2(1.5-12.00)$ \\
\hline $\mathrm{H}$ & CRP (1-mg/L increment)* & $0.97(0.60-1.60)$ \\
\hline \multirow[t]{2}{*}{ I } & Adiponectin $(10-\mu \mathrm{g} / \mathrm{mL}$ decre & $2.2(0.81-6.00)$ \\
\hline & male & $2.9(0.93-9.10)$ \\
\hline \multirow[t]{3}{*}{$\mathrm{J}$} & $\mathrm{n}(10-\mu \mathrm{g} / \mathrm{mL} \text { decrement })^{*}$ & $0.62-5.00)$ \\
\hline & le & $3.4(1.0-11.0)$ \\
\hline & BMI (5-kg/m² increment)* & $1.5(0.95-2.50)$ \\
\hline \multirow[t]{3}{*}{$\mathrm{K}$} & Adiponectin $(10-\mu \mathrm{g} / \mathrm{mL} \text { decrement })^{*}$ & $1.6(0.57-4.80)$ \\
\hline & Male $v s$ female & $2.4(0.76-7.90)$ \\
\hline & ference $(10-c$ & $1.4(0.95-1.90)$ \\
\hline \multirow[t]{3}{*}{$\mathrm{L}$} & Adiponectin $(10-\mu \mathrm{g} / \mathrm{mL} \text { decrement })^{*}$ & $1.7(0.60-4.90)$ \\
\hline & Male $v s$ female & $1.3(0.31-5.60)$ \\
\hline & Waist/hip ratio ( 0.1 increment $)^{*}$ & $1.8(0.90-3.70)$ \\
\hline
\end{tabular}

Each model only included the covariates for which results are displayed (1-4 covariates in each model), plus age as a continuous variable.

*The odds ratio for a continuous predictor is estimated for a specified difference in that exposure (indicated in parentheses after the predictor).

OR $(95 \% \mathrm{CI})=$ odds ratio $(95 \%$ confidence interval $)$; $\mathrm{BMI}=$ body mass index; CRP $=\mathrm{C}$-reactive protein.

EAC remains present even when adjusting for GERD symptoms, suggesting a different pathway $(5,8)$. In this study of patients referred for endoscopy for clinical indications, we found that deficiency of plasma levels of adiponectin, a peptide secreted primarily from visceral adipocytes, is associated with BE, even after adjusting for duration of GERD symptoms. Male gender is also widely recognized to be a risk factor for both $\mathrm{BE}$ and $\mathrm{EAC}$, but to our knowledge, there has yet to be any documented mechanism for these effects (8). It is possible that the positive association between male gender and BE might be explained, in part, by a low adiponectin level, which is positively associated with both male gender and BE. The magnitude of the estimate of the effect of male gender was reduced after adjusting for either adiponectin or WHR.

Adiponectin is the most abundant gene product of adipocytes, and if it is produced by other human tissues at all, it appears to be produced by them at low levels (19, 31). Adiponectin levels are inversely associated with the presence of colorectal adenomas and with cancers of the colon, stomach, uterus, breast, and prostate $(18,32)$. In a prospective cohort study, low adiponectin was found to be associated with the subsequent development of colorectal cancer (33). Multiple potential signaling pathways for this association have been described (18, 34-36). Adiponectin shares homology with tumor necrosis factor- $\alpha$, acts on distant tissues to promote apoptosis, suppresses proliferation, and suppresses angiogenesis $(18,37,38)$. Therefore, deficiency of adiponectin may be involved in the promotion and 
progression of carcinogenesis. One potential mechanism of action is adiponectin's suppression of the extracellular signalregulated kinases 1 and 2 (ERK 1/2) (35). Subjects with BE have abnormal activation of ERK $1 / 2$ in squamous epithelium, promoting proliferation and inhibiting apoptosis; it has been proposed that failure to downregulate ERK 1/2 might promote a metaplastic response to reflux (36). That failure to downregulate ERK 1/2, and the resultant uncontrolled proliferation, might be due to deficiency of adiponectin. In addition, deficiency of adiponectin might promote uncontrolled esophageal inflammation in the setting of GERD. The lack of an association between BE and levels of CRP (a circulating factor whose levels are also associated with obesity) suggests that the association between BE and deficiency of adiponectin is a specific one and may be causal. Studies of the effects of adiponectin in animal models of esophagitis and in cell line cultures are necessary to determine whether adiponectin deficiency has a causative role in the development of BE and EAC.

Our findings may have been influenced by the use of two imperfect (proxy) measures of visceral fat volume, waist circumference and WHR. Adjusting for those two measures may not have completely controlled for abdominal obesity, and adiponectin's attenuation of the estimated effect of waist circumference or WHR for BE could be due to a closer approximation of visceral fat volume by adiponectin levels than by either of those measures. Given the small sample size and the matched design, we may not have completely adjusted for confounders, and this study cannot provide a precise estimate of the hypothesized adiponectin effect on BE. Nonetheless, the fact that low adiponectin remains associated with $\mathrm{BE}$ even when adjusting for GERD suggests a mechanism for the association of visceral fat and BE, aside from the one promoting GERD. Adipocytes secrete many factors into the circulation, many of which have effects on inflammation and some of which might also influence metaplasia or progression of neoplasia. Adiponectin is unlikely to be the only such factor to be associated with BE. Levels of adiponectin are likely to be closely associated with levels of these other unmeasured secreted factors. Our results suggest that the effect of adiponectin may have been confounded by covariates such as obesity and male gender, and we cannot rule out that the adjusted association was a chance finding. Thus, our results suggest that adiponectin and/or abdominal obesity affect the risk of $\mathrm{BE}$, but we cannot precisely separate their effects in this study due to the small sample size. Another limitation is that the control group included patients with multiple indications for endoscopy rather than a specific population at risk for $\mathrm{BE}$, and that might have introduced selection bias in the estimation of effects, but the direction and magnitude of such bias is difficult to predict. However, an analysis restricted to subjects with GERD at least once per week (the group of patients who are recommended to undergo screening for BE) showed similar results. Furthermore, this study cannot determine whether adiponectin deficiency is associated with $\mathrm{BE}$ among subjects without GERD. Finally, the study is limited by temporal ambiguity as the measurement of adiponectin did not precede the development of BE.

In summary, we observed that among patients referred for endoscopies, most with GERD, those diagnosed with BE have lower adiponectin levels, on average, than do those without BE. This association may mean that a lower adiponectin level increases the risk of $\mathrm{BE}$, but additional research is needed to make a causal inference. Thus, our findings might partly explain the effects of abdominal obesity and male gender on BE. The relentless obesity epidemic may portend a progressively rising incidence of EAC over the coming decades. Prevention of mortality from EAC will require a fuller understanding of the risk factors and pathogenesis for this cancer type. Identification of relations with additional secreted factors might be exploited to develop panels of biomarkers for the identification of patients at risk for $\mathrm{BE}$ and $\mathrm{EAC}$ or for the development of novel chemopreventive strategies for EAC.

\section{ACKNOWLEDGMENTS}

The study was funded by the 2005 Clinical Research Award from the GlaxoSmithKline Institute for Digestive Health. John M. Inadomi is funded by the National Institutes of Health, National Cancer Institute (R01 CA106773). We are indebted to Roger Grekin, M.D., for the use of his laboratory space and advice, Alan Vollmer for his laboratory assistance, and Stephen Chensue, M.D., for access to the clinical laboratory of the Ann Arbor VAMC. We appreciate the direction offered by Dean Brenner, M.D., and David Beer, Ph.D., for generating the hypothesis.

\section{STUDY HIGHLIGHTS}

\section{What Is Current Knowledge}

- Obesity is associated with Barrett's esophagus (BE) and esophageal adenocarcinoma.

- This relationship is generally believed to be mediated by gastroesophageal reflux disease (GERD).

- Adiponectin is secreted by adipocytes, and its plasma levels are inversely related to obesity.

- Adiponectin may suppress tumorgenesis, and its circulating levels are inversely related to the risk of a number of epithelial cancers.

\section{What Is New Here}

- Circulating levels of adiponectin are inversely associated with BE among patients referred for endoscopy.

- The association between adiponectin level and BE does not appear to be due entirely to confounding by GERD or other measured risk factors for BE.

- Rather than simply a mechanical effect of obesity promoting GERD, the effect of obesity on the risk of BE might be mediated by adiponectin and other circulating factors. 
Reprint requests and correspondence: Joel H. Rubenstein, M.D., M.Sc., VA Medical Center 111-D, 2215 Fuller Road, Ann Arbor, MI 48105.

Received May 31, 2007; accepted December 31, 2007.

\section{REFERENCES}

1. El-Serag HB, Mason AC, Petersen N, et al. Epidemiological differences between adenocarcinoma of the oesophagus and adenocarcinoma of the gastric cardia in the USA. Gut 2002;50:368-72.

2. Lagergren J, Bergstrom R, Lindgren A, et al. Symptomatic gastroesophageal reflux as a risk factor for esophageal adenocarcinoma. N Engl J Med 1999;340:825-31.

3. Sampliner RE. Updated guidelines for the diagnosis, surveillance, and therapy of Barrett's esophagus. Am J Gastroenterol 2002;97:1888-95.

4. Portale G, Peters JH, Hagen JA, et al. Comparison of the clinical and histological characteristics and survival of distal esophageal-gastroesophageal junction adenocarcinoma in patients with and without Barrett mucosa. Arch Surg 2005; 140:570-4.

5. Hampel H, Abraham NS, El-Serag HB. Meta-analysis: Obesity and the risk for gastroesophageal reflux disease and its complications. Ann Intern Med 2005;143:199-211.

6. Wong A, Fitzgerald RC. Epidemiologic risk factors for Barrett's esophagus and associated adenocarcinoma. Clin Gastroenterol Hepatol 2005;3:1-10.

7. La Vecchia C, Negri E, Lagiou P, et al. Oesophageal adenocarcinoma: A paradigm of mechanical carcinogenesis? Int J Cancer 2002;102:269-70.

8. Lagergren J. Controversies surrounding body mass, reflux, and risk of oesophageal adenocarcinoma. Lancet Oncol 2006; 7:347-9.

9. Corley DA, Kubo A, Levin TR, et al. Abdominal obesity and body mass index as risk factors for Barrett's esophagus. Gastroenterology 2007;133:34-41; quiz 311.

10. El-Serag HB, Kvapil P, Hacken-Bitar J, et al. Abdominal obesity and the risk of Barrett's esophagus. Am J Gastroenterol 2005; 100:2151-6.

11. Edelstein ZR, Farrow DC, Bronner MP, et al. Central adiposity and risk of Barrett's esophagus. Gastroenterology 2007;133:403-11.

12. Chen SC, Chou CK, Wong FH, et al. Overexpression of epidermal growth factor and insulin-like growth factor-I receptors and autocrine stimulation in human esophageal carcinoma cells. Cancer Res 1991;51:1898-903.

13. Liu YC, Leu CM, Wong FH, et al. Autocrine stimulation by insulin-like growth factor I is involved in the growth, tumorigenicity and chemoresistance of human esophageal carcinoma cells. J Biomed Sci 2002;9:665-74.

14. Festa A, D'Agostino R Jr, Tracy RP, et al. Elevated levels of acute-phase proteins and plasminogen activator inhibitor1 predict the development of type 2 diabetes: The Insulin Resistance Atherosclerosis Study. Diabetes 2002;51:11317.

15. Somasundar P, Riggs D, Jackson B, et al. Leptin stimulates esophageal adenocarcinoma growth by nonapoptotic mechanisms. Am J Surg 2003;186:575-8.

16. Stattin P, Lukanova A, Biessy C, et al. Obesity and colon cancer: Does leptin provide a link? Int J Cancer 2004;109:149-52.

17. de Martel C, Haggerty TD, Corley DA, et al. Serum ghrelin levels and risk of subsequent adenocarcinoma of the esophagus. Am J Gastroenterol 2007;102:1166-72.
18. Kelesidis I, Kelesidis T, Mantzoros CS. Adiponectin and cancer: A systematic review. Br J Cancer 2006;94:1221-5.

19. Arita Y, Kihara S, Ouchi N, et al. Paradoxical decrease of an adipose-specific protein, adiponectin, in obesity. Biochem Biophys Res Commun 1999;257:79-83.

20. Yildiz BO, Suchard MA, Wong ML, et al. Alterations in the dynamics of circulating ghrelin, adiponectin, and leptin in human obesity. Proc Natl Acad Sci U S A 2004;101:104349.

21. Shea SA, Hilton MF, Orlova C, et al. Independent circadian and sleep/wake regulation of adipokines and glucose in humans. J Clin Endocrinol Metab 2005;90:2537-44.

22. Bottner A, Kratzsch J, Muller G, et al. Gender differences of adiponectin levels develop during the progression of puberty and are related to serum androgen levels. J Clin Endocrinol Metab 2004;89:4053-61.

23. Gavrila A, Chan JL, Yiannakouris N, et al. Serum adiponectin levels are inversely associated with overall and central fat distribution but are not directly regulated by acute fasting or leptin administration in humans: Crosssectional and interventional studies. J Clin Endocrinol Metab 2003;88:4823-31.

24. Pischon T, Hotamisligil GS, Rimm EB. Adiponectin: Stability in plasma over 36 hours and within-person variation over 1 year. Clin Chem 2003;49:650-2.

25. Lagergren J, Bergstrom R, Nyren O. Association between body mass and adenocarcinoma of the esophagus and gastric cardia. Ann Intern Med 1999;130:883-90.

26. Festa A, D'Agostino R Jr, Howard G, et al. Chronic subclinical inflammation as part of the insulin resistance syndrome: The Insulin Resistance Atherosclerosis Study (IRAS). Circulation 2000;102:42-7.

27. Erlinger TP, Platz EA, Rifai N, et al. C-reactive protein and the risk of incident colorectal cancer. JAMA 2004;291:58590.

28. Chak A, Faulx A, Eng C, et al. Gastroesophageal reflux symptoms in patients with adenocarcinoma of the esophagus or cardia. Cancer 2006;107:2160-6.

29. Buskens CJ, Hulscher JB, van Gulik TM, et al. Histopathologic evaluation of an animal model for Barrett's esophagus and adenocarcinoma of the distal esophagus. J Surg Res 2006; 135:337-44.

30. Jeon J, Luebeck EG, Moolgavkar SH. Age effects and temporal trends in adenocarcinoma of the esophagus and gastric cardia(United States). Cancer Causes Control 2006;17:97181.

31. Maeda K, Okubo K, Shimomura I, et al. cDNA cloning and expression of a novel adipose specific collagen-like factor, apM1 (AdiPose Most abundant gene transcript 1). Biochem Biophys Res Commun 1996;221:286-9.

32. Otake S, Takeda H, Suzuki Y, et al. Association of visceral fat accumulation and plasma adiponectin with colorectal adenoma: Evidence for participation of insulin resistance. Clin Cancer Res 2005; 11:3642-6.

33. Wei EK, Giovannucci E, Fuchs CS, et al. Low plasma adiponectin levels and risk of colorectal cancer in men: A prospective study. J Natl Cancer Inst 2005;97:1688-94.

34. Wang $\mathrm{Y}, \mathrm{Lam} \mathrm{K}, \mathrm{Xu} \mathrm{J}$, et al. Adiponectin inhibits cell proliferation by interacting with several growth factors in oligomerization-dependent manner. J Biol Chem 2005;280:18341-7.

35. Wulster-Radcliffe MC, Ajuwon KM, Wang J, et al. Adiponectin differentially regulates cytokines in porcine macrophages. Biochem Biophys Res Commun 2004;316:924-9.

36. Souza RF, Shewmake KL, Shen Y, et al. Differences in ERK activation in squamous mucosa in patients who have 
gastroesophageal reflux disease with and without Barrett's esophagus. Am J Gastroenterol 2005;100:551-9.

37. Lazar MA. How obesity causes diabetes: Not a tall tale. Science 2005;307:373-5.

38. Yokota T, Oritani K, Takahashi I, et al. Adiponectin, a new member of the family of soluble defense collagens, negatively regulates the growth of myelomonocytic progenitors and the functions of macrophages. Blood 2000;96:1723-32.

\section{CONFLICT OF INTEREST}

Guarantor of the article: Joel H. Rubenstein, M.D., M.Sc. Specific author contributions: Joel H. Rubenstein developed the hypothesis and research plan, directed the recruitment and enrollment, performed and interpreted the statistical analyses, and drafted the manuscript. Anne Dahlkemper recruited and enrolled the subjects, processed the blood sam- ples for storage, and managed the data. John Y. Kao oversaw the measurement of adiponectin and edited the manuscript. Min Zhang performed the measurements of adiponectin. Hal Morgenstern contributed to the research plan, statistical analysis plan, and interpretation of the results and edited the manuscript. Laurence McMohan contributed to the research plan and interpretation of the results and edited the manuscript. John M. Inadomi contributed to the development of the hypothesis and research plan and interpretation of the results and edited the manuscript.

Financial support: Joel H. Rubenstein is supported by a GlaxoSmithKline Institute for Digestive Health Clinical Research Award and John M. Inadomi is supported by a grant from the National Institutes of Health, National Cancer Institute (R01 CA106773).

Potential competing interests: None. 